\title{
Evolution of bower building in Lake Malawi cichlid fish: phylogeny, morphology, and behavior
}

\section{Ryan A. York ${ }^{1 *}$, Chinar Patil ${ }^{2}$, C. Darrin Hulsey ${ }^{3}$, Onyemaechi Anoruo ${ }^{1}$, J. Todd Streelman ${ }^{2 *}$ and Russell D. Fernald ${ }^{1}$}

${ }^{1}$ Department of Biology, Stanford University, Stanford, CA, USA

2 School of Biology, Georgia Institute of Technology, Atlanta, GA, USA

${ }^{3}$ Department of Ecology and Evolution, University of Tennessee Knoxville, Knoxville, TN, USA

\section{Edited by:}

Devi Meian Stuart-Fox, University of Melbourne, Australia

Reviewed by:

Carmelo Fruciano, University of Konstanz, Germany

Topi K. Lehtonen, University of Turku, Finland

\section{${ }^{*}$ Correspondence}

Ryan A. York, Department of

Biology, Stanford University, 371

Serra Mall, Stanford, CA 94305, USA

e-mail: ryanyork@stanford.edu;

J. Todd Streelman, Petit Institute for

Bioengineering and Bioscience,

Georgia Institute of Technology, 310

Ferst Drive, Atlanta, GA

30332-0230, USA

e-mail: todd.streelman@

biology.gatech.edu
Despite considerable research, we still know little about the proximate and ultimate causes behind behavioral evolution. This is partly because understanding the forces acting on behavioral phenotypes requires the study of species-rich clades with extensive variation in behavioral traits, of which we have few current examples. In this paper, we introduce the bower-building cichlids of the Lake Malawi adaptive radiation, a lineage with over 100 species, each possessing a distinct male extended phenotype used to signal reproductive fitness. Extended phenotypes are useful units of analysis for the study of behavior since they are static structures that can be precisely measured within populations. To this end we recognize two core types of bowers - mounds ("castles") and depressions ("pits"). We employ an established framework for the study of adaptive radiations to ask how traits related to other stages of radiations, macrohabitat and feeding morphology, are associated with the evolution of pit and castle phenotypes. We demonstrate that pits and castles are evolutionarily labile traits and have been derived numerous times in multiple Malawi genera. Using public ecological and phenotypic data sets we find significant and correlated differences in macrohabitat (depth), sensory ability (opsin expression), and feeding style (jaw morphology and biomechanics) between pit-digging and castle-building species. Phylogeny-corrected comparisons also show significant differences in several measures of jaw morphology while indicating non-significant differences in depth. Finally, using laboratory observations we assay courtship behaviors in a pit-digging (Copadichromis virginalis) and a castle-building species (Mchenga conophoros). Together, these results show that traits at multiple biological levels act to regulate the evolution of a courtship behavior within natural populations.

Keywords: Malawi cichlids, extended phenotype, bowers, social behavior, ethogram, evolution of behavior, jaw morphology, adaptive radiation

\section{INTRODUCTION}

Understanding the evolution of social behavior requires integration across diverse disciplines and methods (Tinbergen, 1963; Robinson et al., 2008; O'Connell and Hofmann, 2011; Hofmann et al., 2014) to identify and understand the proximate and ultimate mechanisms responsible. Given increased availability of data sets that include diverse species, several groups have used multidisciplinary methods to identify traits that regulate social behavior among several taxa (Goodson, 2005; Pollen et al., 2007; Lefebvre and Sol, 2008). A major constraint on such comparative approaches though is the limited number of clades of organisms with significant variation of described traits at multiple biological levels. Ideally, we would like to analyze clades rich with species displaying high levels of diversity in brain anatomy, function, genetics, and social behavior, allowing multi-dimensional comparisons of traits. Such an approach also requires use of appropriate modern molecular and neurobiological methods.

Bower-building cichlid fish of Lake Malawi are an outstanding example of a clade of species appropriate for discovering the relationships amongst multiple variables that have shaped important differences in this diverse collection of species over evolutionary time. The East African cichlid fish species flocks are one of evolution's most impressive adaptive radiations. In particular, the Lake Malawi flock has over 500 species that evolved within the last 5 million years, displaying one of the most rapid rates of speciation known amongst vertebrates (Brawand et al., 2014). Cichlids are renowned for their high levels of phenotypic diversity across many well-studied traits including jaw and trophic morphology (Kassam et al., 2004; Albertson et al., 2005; Hulsey et al., 2006; Muschick et al., 2011; Gunter et al., 2013), vision (Hofmann et al., 2010; O'Quin et al., 2010), and sex determination (Roberts et al., 2009; Parnell and Streelman, 2013). Although it is wellknown that these species also exhibit many remarkably diverse patterns of behavior, systematic analyses of these traits across taxa are rare (Barlow, 2008). One of the most conspicuous and unique behavioral traits is the building of spawning nests (bowers) by the sand-dwelling species of Lake Malawi (McKaye, 1991; McKaye et al., 2001). Cichlid bowers are extended phenotypes (Dawkins, 
1992), employed in a manner similar to the eponymous mating structures of bowerbirds (McKaye, 1991). All endemic Malawi cichlid species are maternal mouth brooders and most species of the sand and pelagic lineages use bowers for mating displays and sites for egg fertilization (Kidd et al., 2006). Bower shapes and sizes are thought to be species-specific and are used to distinguish among sets of closely related species (Stauffer et al., 1993).

Cichlid bowers have been categorized into at least ten basic forms, ranging in complexity from a small depression to elaborate series of turrets and pits measuring several meters in diameter (McKaye et al., 2001). Structurally bowers are made of the basic elements of depressions and mounds as evidenced by observations in the field literature (McKaye, 1991; Stauffer et al., 1993; McKaye et al., 2001). We refer these basic forms here as "pits" and "castles." A somewhat rarer form of bowers also exist which combine both elements and we refer to as "pit-castles." Distinct behavioral repertoires also appear to be associated with differences in bower type between species (McKaye et al., 2001). The presence of pit and castle bower types varies widely and intragenera differences are common, suggesting that parallel evolution of each bower type has occurred multiple times (Figure 1). This repeated parallelism is similar to that of other well-studied traits such as number and properties of photoreceptor opsins (Parry et al., 2005; Hofmann et al., 2009), jaw morphology (Albertson et al., 2003), and microhabitat use (Huber et al., 1997). It also mirrors the evolution of analogous trophic ecotypes (craniofacial morphology) associated with diet in Lakes Malawi, Victoria, and Tanganyika (Gunter et al., 2013). It is important to note that bower building does not reflect variation of social organization between species but rather the diversity of social courtship signals displayed by Malawi cichlids. For this reason bower building is a good model for studying the evolution of courtship behavior. A suggested framework for understanding the evolution of such diverse traits is the radiation in stages model first proposed by Streelman and Danley (2003). This model posits that within adaptive radiations, species diverge along three axes: Macrohabitat diversification (e.g., spatial distribution), trophic adaptation (e.g., feeding preference), and elaboration of communication signals, assumed to be largely driven by sexual selection including bower building. An unresolved question in the study of such sequential adaptive radiations is to what extent traits evolved in the first two stages affect innovations in the final stage (intra-species communication). This is an important issue since variations in intra-species communication may play different roles in speciation depending on the unique qualities of a given radiation. For example Streelman and Danley (Streelman and Danley, 2003) posited that signaling traits (e.g., nuptial color), independent of morphology, fuelled evolutionary radiation in certain lineages (e.g., Malawi rock-dwelling cichlids), but not others (e.g., Darwin's finches). A second question revolves around exactly how the forces of natural and sexual selection interact during evolutionary radiation. For example do adaptations related to feeding strategy constrain the elaboration of species-specific signals? Or how do differences in abiotic environment (e.g., light) influence nervous systems and their social behavioral output? In particular, Kidd and colleagues (Kidd et al., 2006), writing in the context of Malawi sand-dwelling cichlids, suggested that traits elaborated by selection were likely to be more "intertwined" than expressed in Streelman and Danley's general model.

Following on from this general framework, we assessed how manifold traits evolved in Malawi sand-dwelling cichlids, and hypothesized that traits related to macrohabitat use and feeding style might be correlated with differences in bower type. To test this we analyzed measures of phenotypes representing each of these trait types. Using extant data sets from multiple sources we assayed divergence in water depth at which these animals live. Given that depth is a major determinant of macrohabitat differences in lake ecosystems, we predicted that environmental variation within different depths (e.g., light, food availability, etc.) would correlate with different bower types. If systematic variations in depth of occurrence were to be observed we hypothesized that differences in visual sensitivity between species would also exist. To answer this question, we tested for variation in the expression of photoreceptor opsins between pit and castle builders. Divergence in craniofacial morphology was then assayed in order to test for functional differences related to trophic style and jaw mechanics. Finally, to gain insight into how courtship repertoires might differ between species with different bower types, we characterized the behavior of two species using detailed behavioral descriptions (ethograms) for one pit-digger (Copadichromis virginalis) and one castle-builder (Mchenga conophoros) (Figure 2) in the lab. Since previous work has identified unique forms of male courtship signals within multiple genera of cichlids we hypothesized that species-specific courtship behaviors may exist within bower-building clades (McKaye et al., 2001; Albertson et al., 2003).

We show that multiple traits segregate with parallel innovations of the basic bower types. These observations represent an elegant example of evolutionary processes exploiting highly similar genetic substrates to achieve diverse behavioral outcomes. While our results are striking, they highlight just a part of the interplay between biological domains that regulate bower building. The bower-building cichlids of Lake Malawi thus offer unique opportunities to address basic questions about the genetic, neural, and ecological bases of vertebrate behavioral evolution.

\section{RESULTS}

\section{BOWER DEPTH DISTRIBUTION ANALYSIS}

Differences in macrohabitat were assayed using published measures of maximum and minimum depths of occurrence for 55 species of bower-building cichlids (Castle $n=27$; Pit $n=21$; Pit-castle $n=7$ ) (Huber et al., 1997; Duponchelle et al., 2000; Albertson et al., 2003; Streelman and Danley, 2003; Kocher, 2004; Konings, 1990, 2000, 2007). A bootstrap ANOVA (see Methods) showed significant differences in maximum depth $(p=0.021$; bonferroni corrected) and a strong trend toward divergence in range of depths (maximum minus minimum depth; $p=0.06$; bonferroni corrected) between pit and castle species whereas minimum depth does not show significance $(p=0.13$; bonferroni corrected). Pairwise comparisons of pit/pit-castle and castle/pitcastle species do not reveal any significant differences. These results indicate that castle-building species tend to occur at shallower maximum depths with less variation in depth range than pit-digging species. 


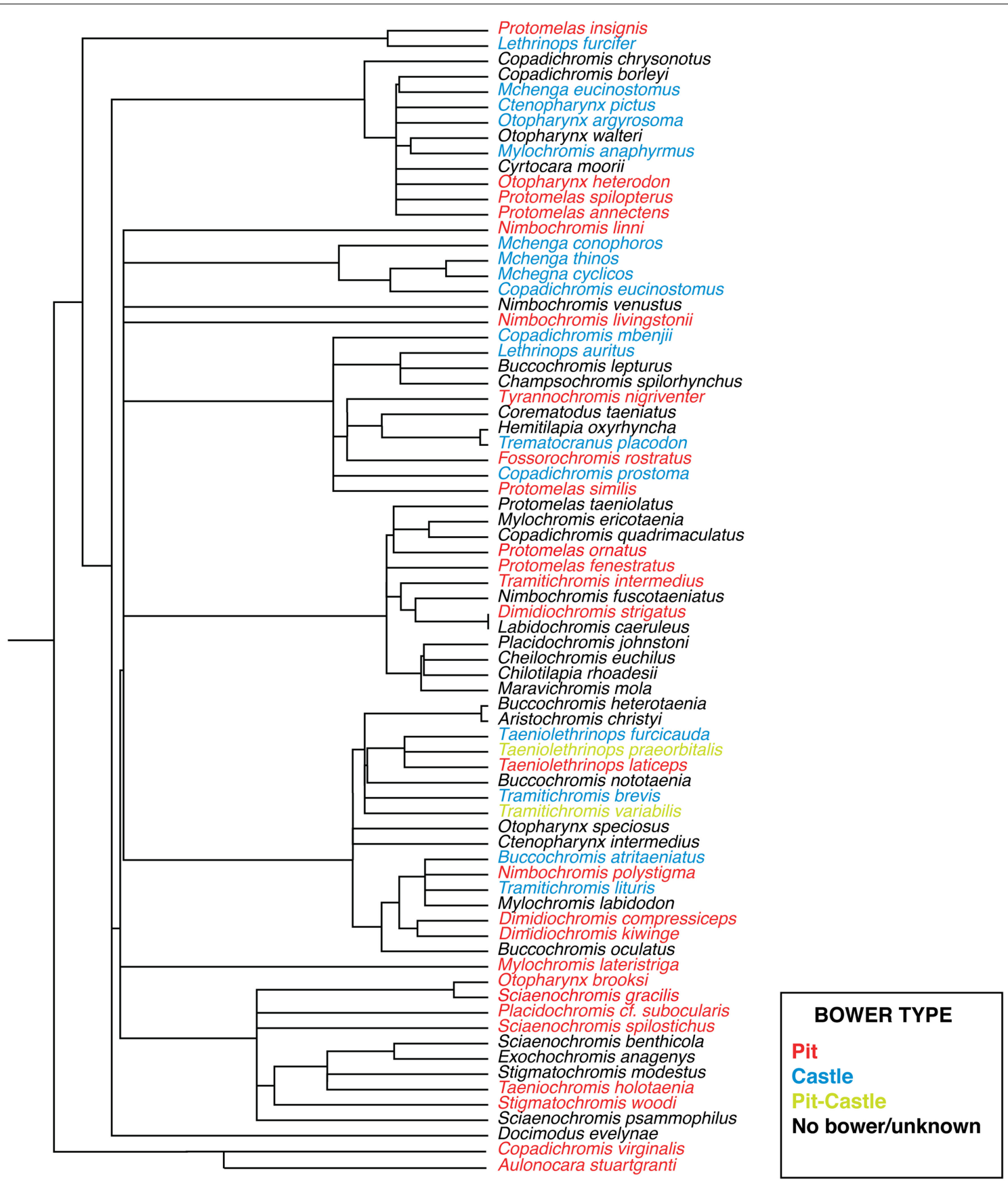

FIGURE 1 | Phylogeny of sand-dwelling Lake Malawi cichlids. Bower types are coded by color (blue, castle; red, pit; yellow, pit-castle; black, no bower/unknown). Adapted with permission from Macmillan Publishers Ltd.: Nature (Wagner et al., 2012), copyright 2012.

The relationship between opsin gene expression and pitdigging $(n=11)$ and castle-building $(n=8)$ species was assayed using expression data for 6 opsins reported for Malawi cichlids (Parry et al., 2005; Hofmann et al., 2009). The opsin SWS2b is significantly more highly expressed in pit-diggers than castlebuilders ( $p=0.042$; bonferroni corrected). No other opsins show significant differential expression between groups. The opsin SWS2b, along with SWS1 and SWS2a, is expressed in single cones, which are genetically and functionally distinct from the double cones in which the opsins $\mathrm{Rh} 2 \mathrm{~B}, \mathrm{Rh} 2 \mathrm{~A}$, and LWS occur. Since single-cone opsins are sensitive to shorter wavelengths, we tested for differences in single and double cone sensitivities that might corroborate the differential expression of SWS2b. Using the same ANOVA method as above we assayed single cone sensitivity [pit $(n=12)$; castle $(n=9)$ ] and double cone sensitivity [pit $(n=10)$; castle $(n=9)$ ]. We find that castle-builders have 

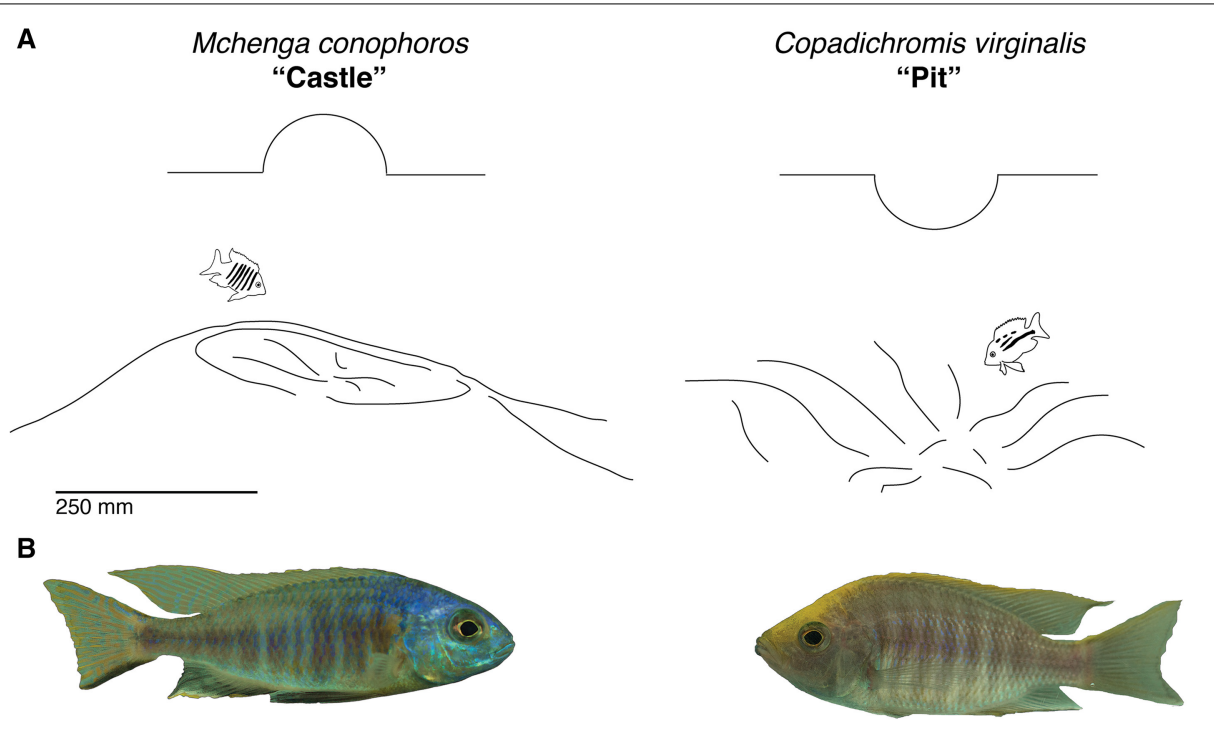

FIGURE 2 | Basic bower types. (A) Castle and pit phenotypes as represented by the species Mchenga conophoros and Copadichromis virgnalis. (B) Photos of male Mchenga conophoros and Copadichromis virginalis.

a significantly shorter single-cone wavelength sensitivities ( $p=$ 0.028 ; bonferroni corrected) while no significant difference in double-cone sensitivity was found. Lake Malawi cichlids tend to express opsins in three common combinations ("palettes"): UV, violet, and blue (Hofmann et al., 2009). Using the UV palette designations from Hofmann et al. (2009), we identified a more common occurrence of a UV three-opsin palette in castle-building species (castle-builders: 6/8 species; pit-diggers: $2 / 9$ species; $p=0.057$ ).

Taken together, these results show that species that build castle and pit-castle bower types occur at shallower depths and have smaller ranges of occurrence than species that dig pits (Figure 3). Castle and pit species also tend to have divergent visual capacities reflected in differences in SWS2b expression, single cone wavelength sensitivity, and opsin palette.

\section{JAW MORPHOLOGY}

To test whether jaw morphology segregates with bower type we performed comparisons of pit-digging $(n=38)$ and castlebuilding $(n=13)$ species for an array of jaw and facial traits known to have functional implications in cichlids and other teleost fishes, including mouth opening gape, degree of upper jaw protrusion and simple and complex lever systems that characterize trade-offs between jaw speed and jaw strength (Hulsey and Wainwright, 2002; Alfaro et al., 2005; Hulsey and Garcia De Leon, 2005; Parnell et al., 2008; Hulsey et al., 2010).

Of these parameters, we find that maxillary kinematic transmission (KT), which is a metric of upper jaw protrusion, differs significantly between groups ( $p=0.017$; bonferroni corrected) with castle-builders possessing greater KT than pitdiggers (Figure 4). Maxillary KT is negatively correlated with the length of the ascending arm of the premaxilla (Pearson's correlation; $r=-0.309 ; p=0.09$ ), which also differs between castlebuilders and pit-diggers ( $p=0.022$; uncorrected; non-significant

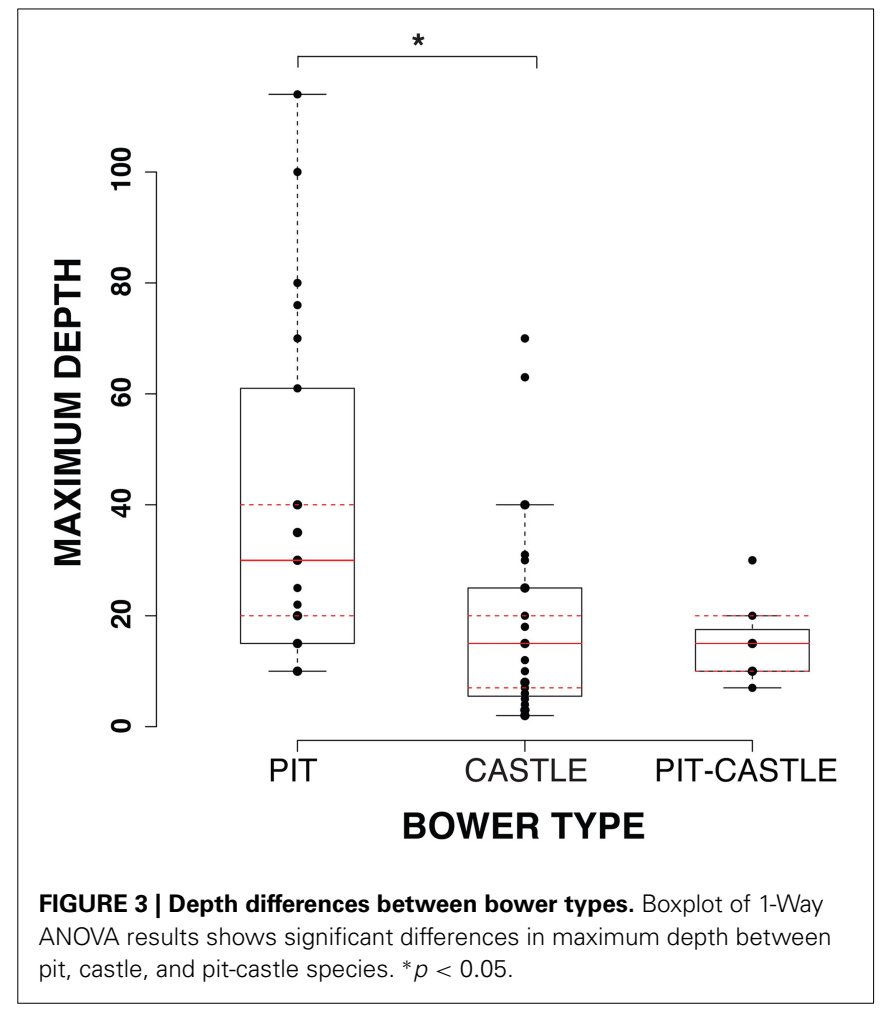

after correction). The increased maxillary KT of castle-builders suggests that they exhibit greater speed of jaw opening. In many fish systems, maxillary KT is positively correlated with protrusion $\mathrm{KT}$, often indicated by a relatively longer ascending arm of the premaxilla. However the correlation in this data set runs opposite to that trend. The relatively larger ascending arm of the premaxilla may serve pit-digging species by orienting their gape toward the 


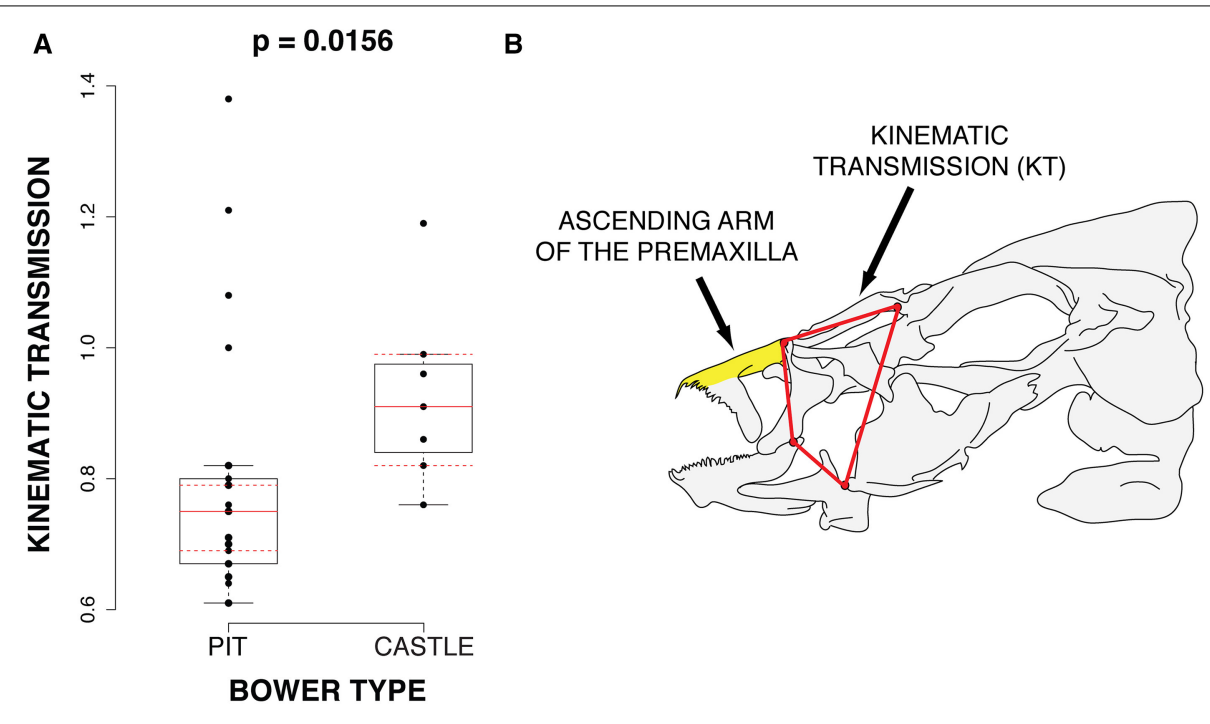

FIGURE 4 | Differences in functional jaw morphology. (A) 4-bar Kinematic transmission is significantly higher in castle-building species. (B) The cichlid anterior jaw. The ascending arm for the premaxilla and 4-bar linkage system (kinematic transmission) are labeled.

substrate, as observed for the Malawi rock-dweller Labeotropheus fuelleborni (Alberston and Kocher, 2001).

\section{CORRECTIONS FOR EVOLUTIONARY HISTORY}

Trait comparisons among species are influenced by evolutionary history such that closely related species are not statistically independent samples. Thus, we also carried out phylogenetic ANOVAs for those traits with enough available data to allow comparisons. Because species are so closely related and segregate ancestral polymorphism, the phylogenetic signal among Malawi cichlid species is weak (Hulsey et al., 2010). Thus we followed a strategy similar to that used by Hulsey and colleagues (Hulsey et al., 2013). Twenty-five sand-dwelling species had enough molecular data to build a phylogenetic hypothesis (see Methods), as well as data for the following traits: gape, length of the ascending arm of the premaxilla, jaw protrusion, opening and closing lever ratios for the lower jaw, 4-bar maxillary KT and the 3 depth values. Because there is uncertainty in the true phylogeny of species, we calculated the mean and variance of $p$-values from phylogenetic ANOVA, comparing pit vs. castle species, across 100 trees. Using this conservative data set (limited by the availability of data) and approach, we found that the length of the ascending arm of the premaxilla was statistically different between pit and castle species $(p=0.012 \pm 0.006 \mathrm{sd})$ and that both the lower jaw closing ratio ( $p=0.082 \pm 0.024 \mathrm{sd}$ ) and maxillary KT ( $p=0.089 \pm 0.025 \mathrm{sd})$ were nearly so. None of the depth variables approached statistical significance using this smaller data set.

\section{ETHOGRAM COMPARSION}

To identify patterns of courtship behavior that may be correlated with bower types we recorded behavior and constructed ethograms (e.g., behavioral inventories) for the species Copadichromis virginalis (pit-digger) and Mchenga conophoros (castle-builder). Copadichromis virginalis and
Mchenga conophoros are ideal species for identifying speciesspecific behavioral repertoires associated with bower-building since they share much of the same ecology. Both species are part of the Utaka species complex and are similarly defined by planktivorous diets, sexual dimorphism, comparatively small size, and seasonal breeding at shallow depths (Fryer and Iles, 1972). Differences in courtship may therefore be ascribed to variation in behavior, as opposed to other traits, with relative confidence.

We identified 17 shared behaviors between the two species:

Free swim: Oriented locomotion.

Sand manipulation: Pick up sand with mouth and deposit randomly, distinct from feeding.

Freeze: Cessation of swimming.

Flare: Extension of opercula, mouth, dorsal fin, and ventral fins.

Approach: Quickly swim toward another fish.

Chase: Rapidly pursue another fish.

Display: Male ceases swimming and orients perpendicular to a female.

Lead: Male quickly swims in front of female in direction of his bower.

Quiver: Male orients perpendicular to a female assuming a rigid body position and rapidly vibrates lateral muscles.

Bower-circling bout: Male and female orient anti-parallel to each other and circle while quivering within the male's bower. Frontal threat: Spread opercula, lowered chin.

Lateral/Circling threat: Males orient anti-parallel to each other and circle each other.

Spawn: In anti-parallel orientation to a male female lays eggs and collects them in mouth while male orients toward female's oviduct, alternating between lateral display and egg fertilization.

Flee: Rapid swimming away in order to escape. 
Feed: Collect food by sifting through sand for particles. Chafe: Swim rapidly along sand, orienting laterally to allow side of body to scratch the sand surface.

Hide: Swim rapidly underneath sand surface in order to completely cover the body.

In addition to these behaviors we also note several species specific behaviors related to bower building:

Build (M. conophoros): Male picks up sand anywhere in tank and deposits in stereotypical location (castle) within his territory.

Dig (C. virginalis): Male picks up sand from stereotypical location (pit) within his territory and deposits anywhere in tank.

\section{ANALYSIS OF BOWER BEHAVIOR AND BEHAVIORAL TRANSITIONS}

To assess differences in bower behavior between $M$. conophoros (MC) and C. virginalis (CV), we first focused on the frequencies of building $v s$. digging during periods of peak bower activity. Peak bower activity was defined as the hour of highest activity measured from a 6-day window, 3 days before and 3 days after a spawning event. Ten males of each species were scored for bower construction behaviors. At peak bower activity, MC males build at twice the rate per hour, compared to the frequency of digging for $\mathrm{CV}(p=0.0001$; Figure 5A).

To explore other related aspects of male courtship and the transitions between behaviors, a different group of males ( $n=$ 3/group) were filmed in 30-min windows during active courting and nine behaviors were observed during these recordings: approach, build, chase, display, free swim, lead, quiver, flare, and sand manipulation. To test for quantitative differences in behavior between $\mathrm{MC}$ and $\mathrm{CV}$ we tested pairwise comparisons for each behavior and behavioral transition probabilities using the same bootstrap method as above. We find no significant differences between $\mathrm{MC}$ and $\mathrm{CV}$, possibly due to our sample size or to high levels of variability within each species. Despite this we do observe interesting qualitative trends in the frequency and transitions of behaviors. Notably, we observe an average up to twice as many display behaviors (approach, flare, display) in CV than MC. Conversely, MC males perform proportionally more behaviors related to castle building and territoriality (build, chase, lead, quiver). MC males also on average perform over 20 times more sand manipulations that CV males (Figure 5B).

These differences in behavioral frequencies correspond to differences in the probability of transitioning from one behavior to another. Display behaviors are tightly linked in CV. For example, displays are followed by flares $\sim 85 \%$ of the time, over twice that which is observed in MC. This result is corroborated by the low amount of entropy-a measure of sequence predictability $(0=$ highly deterministic/maximum predictability; 1 = highly chaotic/minimum predictability) — for display in CV males (0.257). Behaviors related to oral movement of sand (sand manipulation and build) both occur at higher frequencies in MC and are more likely to be repeated. This is highlighted the fact that build follows itself $32 \%$ of the time or, in other words, multiple mouthfuls of sand deposited in a single bout of bower-building.
These results suggest two possible strategies: CV males opt for higher levels of display during courtship while MC males place more energy in behaviors associated with bower construction.

\section{DISCUSSION}

We found significant differentiation in multiple traits between pit-digging and castle-building species. These differences occur in traits related to habitat, morphology, and behavior and correspond to specific aspects of extant theories regarding the progression of adaptive radiations (Huber et al., 1997). Phylogenetic analysis shows that bower building is an exceptionally labile trait. The core bower types appear to have been derived multiple times and mirror the patterns of parallel evolution observed for several other non-behavioral phenotypes such as jaw morphology, photoreceptor opsin expression, and trophic preference in East African cichlids (Albertson et al., 2003; Hulsey et al., 2006; Hofmann et al., 2009; Brawand et al., 2014).

\section{PHYLOGENY}

Given visual analysis of the phylogenetic distribution of bower types in Lake Malawi we observe patterns similar to quickly evolving animal architectures in other taxa. For example, bower types in bowerbirds are also very labile and appear to evolve without phylogenetic constraint (Fryer and Iles, 1972; Kusmierski et al., 1997; Uy, 2000; Hansell, 2005). Similar patterns of disconnect between molecular/morphological phylogenies and animal architectures have been observed in systems such as a swiftlets (Lee et al., 1996) and blackflies (Stuart and Hunter, 1998). While in these studies animal architectures could not be used for phylogenetic resolution between genera it has been shown that cichlid bower types can be used as a taxonomic character to discriminate between species within genera (Stauffer et al., 1993). Taken together these observations demonstrate that bower types have an extremely high level of evolutionary plasticity, the importance of which is strongest at the species level. Cichlid bowers then, like bowerbird bowers, may align with the speciation by sexual selection (SSS) hypothesis. In this model, traits driving speciation are largely due to female preference with little accompanying molecular divergence (Schluter and Price, 1993; Stuart and Hunter, 1998; Turner and Burrows, 1995; Uy, 2000). These observations highlight the influence sexual selection may have on bower building across the sand-dwelling lineage of Lake Malawi cichlids and corroborate previous work on this subject (McKaye, 1991; Martin and Genner, 2009).

\section{MACROHABITAT/OPSINS}

Our non-phylogenetic analyses of the depth of occurrence of pitdigging and castle-building species reveal a strong correlation between the core bower types and macrohabitat. Our phylogenetic analyses did not indicate significant differences in depth though believe this is due to a substantially smaller sample size and a decreased representation of bower-building genera. This discrepancy will hopefully be resolved as molecular phylogenetic data become available for more species of Malawi cichlids. It has been shown in multiple systems that depth is important for determining the preferred habitat of radiating species of fish. Divergent events have led to different preferences in depth in many fish 

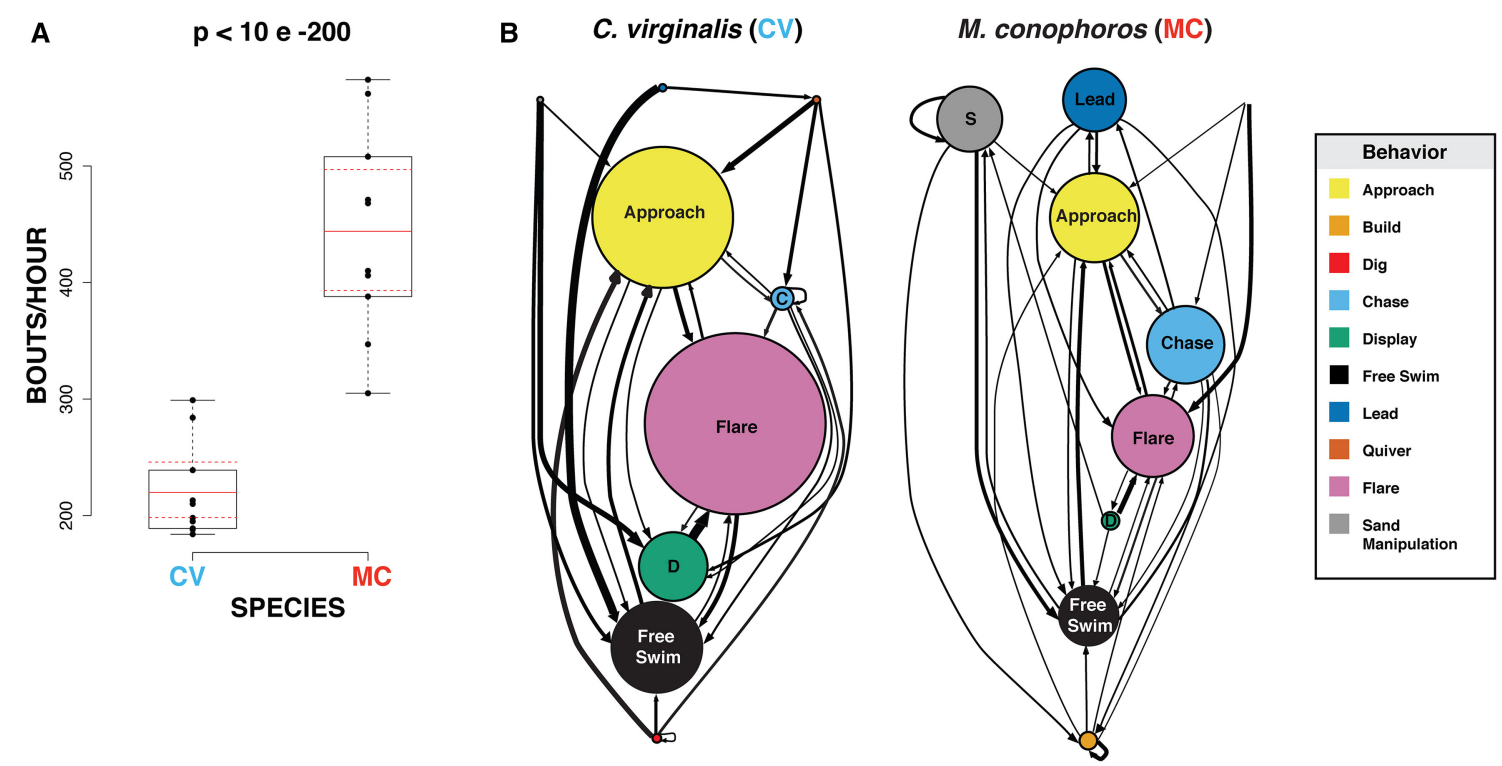

FIGURE 5 | Bower-building and courtship behavior of Mchenga conophoros and Copadichromis virginalis. (A) Mchenga conophoros males perform significantly more building bouts during peak activity compared to Copadichromis virginalis. (B) Node diameter represents average number of occurrences for each behavior. Arrow thickness corresponds to transition probability between behaviors, including repeated behaviors (represented by arrows that originate and terminate onto the same node). For ease of interpretation only behavioral transitions with probability greater than 0.1 are plotted. species including sticklebacks, salmonids, perch, and neotropical cichlids (Rundle et al., 2000; Peichel et al., 2001; Svanbäck and Eklöv, 2002; Bernatchez et al., 2010; Franchini et al., 2014). Similar phenomena have been observed in common ecomorphs between the East African cichlid radiations and in the sand and rock-dwelling lineages of Lake Malawi itself (Moran et al., 1994; Danly and Kocher, 2001; Hulsey et al., 2013; Franchini et al., 2014). While variations in preferred depth lead to differential access to food sources-as is evidenced by the common trophic innovations observed in the stickleback and cichlid radiationsthey also produce varied access to a more fundamental abiotic factor: Light.

For example, alterations in access to light due to anthropogenic eutrophication in Lake Victoria have led to a decrease in cichlid species diversity due to a breakdown of reproductive barriers usually maintained through species-specific visual communication (Seehausen et al., 1997; Magalhaes and Seehausen, 2010). The eutrophication process in Victoria highlights the tight relationship between male nuptial coloration and sensory abilities within species. The nature of this relationship is largely determined by the visual environment, as determined by factors such as depth. This has apparently played an important role in the variable distribution of male coloration and photoreceptor opsins properties amongst Lake Malawi cichlids, and is putatively shaped by sexual selection (Smith et al., 2012).

Bower type may be under similar pressures. Castle and pitcastle species inhabit significantly shallower depths than pitdigging species and on average occur over smaller ranges. Possible biotic factors contributing to the distribution of bower building species might include the aforementioned differences in food availability, inter-species competition, and intra-species visual communication. Abiotic factors such as lake currents, substrate type, and variations in temperature may also contribute.

It is possible that the core bower types require different amounts of light in order to be properly recognized as signals, perhaps in a manner analogous to the recognition of conspecific nuptial coloration (Hofmann et al., 2009). Castle and pit-castle bowers are 3-dimensional structures extending from the lake bottom and, like all underwater objects, their visibility likely benefits from higher levels of radiance contrast at shallower depths (Lythgoe, 1968). Indeed substantial differences in radiance contrast have been observed in Lake Malawi as a function of both depth and substrate type (Sabbah et al., 2011). Ultraviolet light penetrance also varies with depth in aquatic environments and UV sensitivity plays an important role in color communication in Malawi cichlids (Carleton et al., 2000; Dalton et al., 2010). Differences in visual sensitivity between pit and castle species may lead to increased sensitivity to UV spectra in castle-builders. This is indicated by a shorter single cone wavelength sensitivity and higher levels of a UV three-opsin palette in the castle-building species we analyzed. The opsin SWS2b is also significantly lower expressed in castle-builders which has been shown to be indicative of the UV three-opsin palette (Hofmann et al., 2009). These visual sensitivities are likely tuned by factors independent of bower type, examples of which are variation in species color recognition and alternative forms of feeding style (discussed below). Factors such as these though may contribute to a propensity for certain lineages to evolve castle and pit-castle type bowers due to greater capacities for visual recognition of bower protrusions. 
Importantly we did not find significant differential expression of the other five opsins between pit and castle building species. This could be due to as-yet-unknown pressures acting on SWS2b opsin expression in the species we analyzed. Similarly this observation could be due to shared variation within the limited number of species in our data set. Future work exploring the relationships between bower shape and size and variable sensory abilities will be illuminating.

\section{JAW MORPHOLOGY}

Differences in macrohabitat within adaptive radiations often give rise to innovations in jaw morphology and feeding preference. We find evidence for divergence in functional jaw morphology between castle and pit species in both kinematic transmission (KT) levels and length of the functionally associated ascending arm of the premaxilla. These observations fit larger patterns within teleost (bony fish) evolution in which diversification of ecological traits has arisen from biomechanical elaboration of the oral jaw multiple times in the Perciform and Cypriniform lineages (Cooper and Westneat, 2009). Planktivorous (evasive prey) species in Lake Malawi have been shown to have significantly higher maxillary KT than other feeding types, in addition to higher expression levels of UV-sensitive opsins (Hulsey and Garcia De Leon, 2005; Parnell et al., 2008). These observations parallel those made in other planktivorous teleost species that have been shown to possess increased polarization contrast detection in order to detect transparent zooplankton (Sabbah et al., 2010; Kamermans and Hawryshyn, 2011). Notably the planktivorous Utaka (Copadichromis and Mchenga genera) lineage of sand-dwelling cichlids possesses exceedingly good visual capabilities and constitutes a significant proportion of known bowerbuilding species. It is intriguing to consider jaw morphology and feeding style, together with depth and visual acuity, as further traits that might constrain the bower phenotype. Integration of these non-behavioral traits may thus have important effects on the evolution of bower-building and courtship behaviors through their influence on sensory (e.g., vision) and motor (e.g., trophic biomechanical) abilities.

\section{COURTSHIP BEHAVIOR}

The effects of variation in the described traits on behavioral phenotypes are ultimately evident from the behavior of individual organisms within a population. For bower building species, two distinct types of behavioral phenotypes exist: (1) The dynamic patterns of male behavior that construct and use the bower (extended phenotype) and; (2) the resulting bower itself. For the two species studied here both appear to have species-specific nuptial coloration that likely act as reproductive barriers, but the behaviors exhibited have interesting elements of similarity and difference. Our preliminary data suggest that differences may exist in courtship behavior between these species, although differences were not statistically significant due to a small sample size and high variability within species. Nevertheless our results show that CV males appear to construct their bowers less frequently during courtship and instead spend more time engaged in dynamic display behaviors. We observe the opposite pattern in MC in which bower construction and sand manipulation occur more often. However, given the lack statistical differences between $\mathrm{CV}$ and $\mathrm{MC}$, these preliminary results may also be interpreted in the opposite fashion in which both species' behavioral repertoires do not greatly differ despite the large difference in outcome (bower shape). Specifically, both animals are doing exactly the same thing, namely moving substrate from one location to another. Mchenga conophoros (castle-builder; MC), moves substrate from many different locations to one location while Copadichromis virginalis (pit-digger; CV) moves substrate from one location to many locations. The activity of moving substrate from point A to point $\mathrm{B}$ is identical and hence so are the behaviors. Future behavioral work will be useful in illuminating the amount of intraand inter-species variability observed during courtship in these species and others.

\section{CONCLUDING REMARKS}

These data suggest that the bower-building cichlids of Lake Malawi are a uniquely robust system for studying the evolution of courtship behavior. A great deal is known about the diversity of various traits in cichlids in this lake relating to ecology, morphology, development, and sensory physiology. That such diversity arises from a genetic background with extremely low variation (nucleotide diversity of $0.26 \%$ ) (Loh et al., 2008) is particularly intriguing and, taken together with the ability to produce hybrids in laboratory conditions (Muschick et al., 2011), offers unique opportunities to map ecologically-relevant behaviors to genetic loci. The bower-building cichlids also allow analyses that consider the integrated impact of diverse traits on variation in nervous system structure and function.

For example variations in the abiotic and biotic structures of different macrohabitats may drive innovations in traits associated with trophic style such as jaw morphology and visual sensitivity. These changes in morphology and sensory ability may then affect intra-species reproductive signaling due to changes in coloration and visual recognition of conspecifics. Factors within each of these putative stages of adaptive radiation-macrohabitat, trophic preference, intra-species communication-then have the ability to influence aspects of nervous system and molecular evolution (Figure 6). The application of contemporary molecular and neurobiological tools will allow many fundamental questions in social behavior research to be addressed in this most unlikely and beautiful example of evolutionary diversification.

\section{METHODS STATISTICS}

All statistical analyses were performed using the $\mathrm{R}$ language for statistical computing. For each test in which differences between two or more independent measurements were compared a permutation-based (bootstrap) 1-Way ANOVA procedure was used (100,000 permutations). Unless otherwise stated, $p$-values reported in the Results were derived from this test.

\section{DEPTH AND OPSIN ANALYSES}

Minimum and maximum depths of occurrence were recorded from a literature search of published field and laboratory observations for 55 species of bower-building cichlids (Castle $n=$ 27; Pit $n=21$; Pit-castle $n=7$ ). Species from 17 genera were 


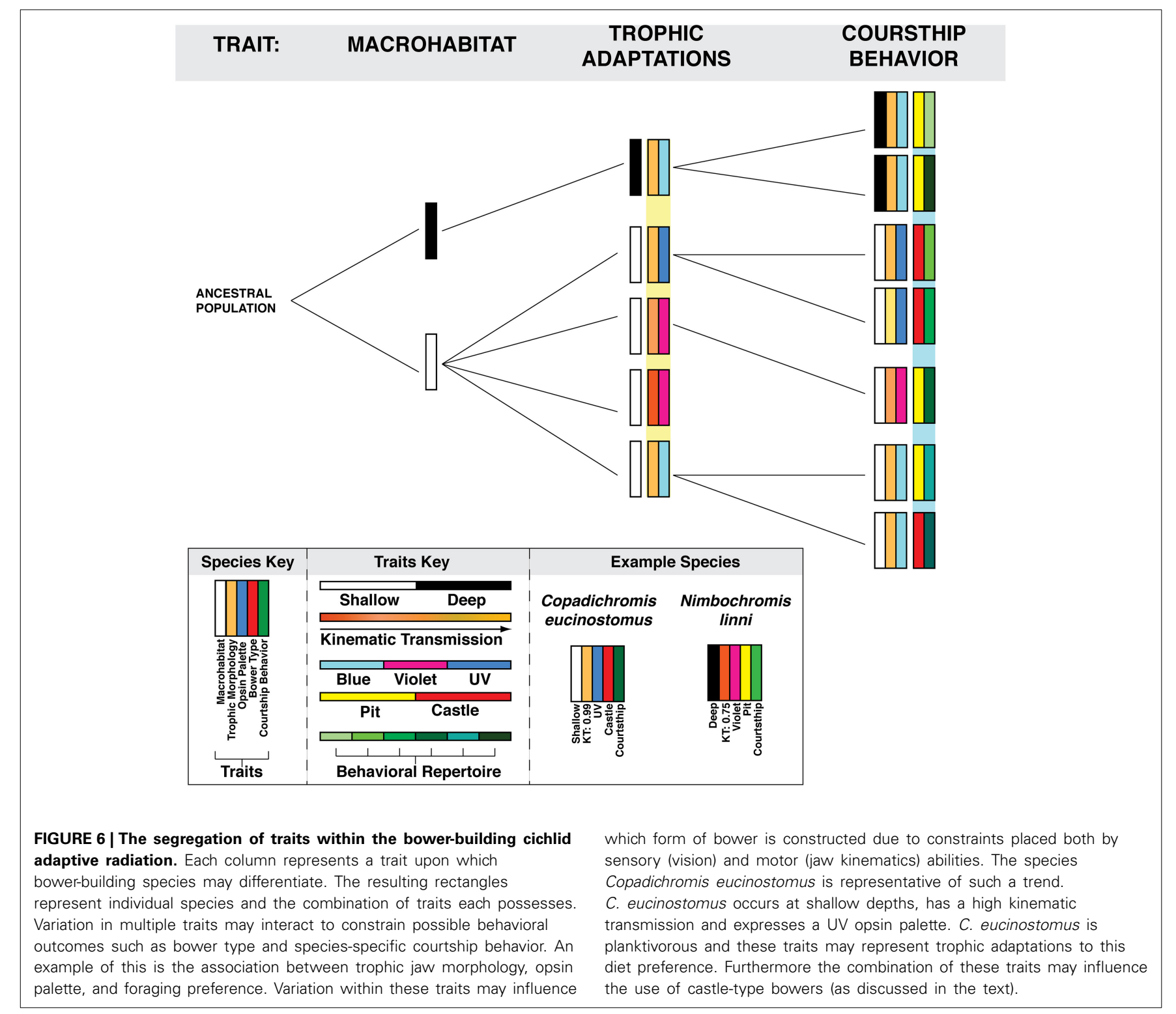

assayed in order to obtain a sample representing the diversity of bower-buidling species as broadly as possible. Depth range was computed from the difference of maximum and minimum depths.

Opsin measurements were procured from the data set produced by Hofmann et al. (2009) from which expression levels for the opsins SWS1, SWS2a, SWS2b, RH2a, RH2b, and LWS were recorded. Single and double-cone sensitivity calculations were recorded from references Hofmann et al. (2009) and Parry et al. (2005). In references Hofmann et al. (2009) and Parry et al. (2005) sensitivities were calculated by taking the ratio of peak spectral sensitivities as measured by microspectrophotometry and the expression of each cone type. Since opsin expression levels and single/double-cone sensitivity data were not all available for all species slightly different combinations of species were used for each test. These data along with those relating to depth were analyzed using the bootstrap 1-Way ANOVA test outlined above. In order to control for multiple testing issues Bonferroni correction was applied to the depth (3 tests) and individual opsin expression (6 tests) analyses. All results for these analyses and each of the other comparative tests are available in Supplementary Table 1.

\section{JAW MORPHOLOGY}

Individual measurements of jaw and facial morphology were made on wild caught fish and averaged for species. Data for single and complex lever systems used here were taken from references Hulsey et al. (2010) and Alfaro et al. (2005). For other traits (e.g., gape, protrusion, length of the ascending arm of the premaxilla), measurements to the nearest $0.1 \mathrm{~mm}$ were recorded in the field using dial calipers. Using the same literature search methods as employed for acquiring the depth data we identified bower-building species within the data set [pit-diggers $(n=$ 
38 ); castle-builders ( $n=13)$ ]. Linear measures were corrected for standard length before statistical analysis.

\section{PHYLOGENETIC HYPOTHESES AND PHYLOGENETIC ANOVA}

To generate a phylogenetic hypothesis for the relationships among as many of the Malawi pit and castle building species as possible, we combined gene sequence data available for the mtDNA control region on Genbank, as well as 30 SNP (single nucleotide polymorphism) loci. The 30 SNPs were among those ascertained from the shotgun sequencing of the genomes of five Lake Malawi cichlids and then genotyped in the cichlid species using a Beckman Coulter SNPstream ${ }^{\mathrm{TM}}$ technology (Beckman Coulter, Inc., Fullerton, CA) as described by Loh et al. $(2008,2013)$.

For the phylogenetic analyses, ModelTest (Posada, 2008) was used to identify the best model of molecular evolution for control region. We also examined our SNPs in a phylogenetic context using methods outlined in Hulsey et al. (2013). Briefly, this method codes each SNP site as 0 (homozygous), 1 (heterozygous), or 2 (homozygous for the other base) based on a random assignment of one homozygous nucleotide being coded as 0 . For instance, AA would be coded as 0 , AT would be coded as 1, and TT coded as 2. Importantly, this SNP character coding allowed us to analyze this data in conjunction with our more traditional analyses of sequence data. We analyzed the SNP coded characters as a single concatenated dataset in MrBayes 3.2 (Ronquist et al., 2012). A key feature of MrBayes is its incorporation of the Lewis (2001) MK model (Lewis, 2001). This model was described for binary morphological data, where it is important to take into account the bias associated with only sampling variable sites. Our SNP data are variable in this way.

The phylogenetic analyses treated the transition-transversion matrices, number of invariant sites, and gamma shape parameters of control region as unlinked or independent. Flat prior probability distribution for all parameters were assumed before analysis. We ran five separate Bayesian analyses for 1,000,000 generations with four Markov chains in each run. We sampled trees from the Markov Chain Monte Carlo (MCMC) search algorithm every 1000 generations. At the end of each analysis, the log-likelihood scores were plotted against generation time to identify the point at which log likelihood values reached a stable equilibrium. In all five, the equilibrium appeared to be reached at approximately 100,000 generations, and therefore, sample points prior to generation 200,000 in each run were discarded as "burn-in" samples. We also examined the effective sample size (ESS) of the likelihoods of each phylogenetic analysis remaining post-burn using Tracer v1.5 (Drummond and Rambaut, 2007) to ensure that values were over 200 thereby ensuring the phylogenetic searches were well mixed.

For each of the five Mr. Bayes runs, we isolated 20 random post-burn-in phylogenies and combined them to generate a file with 100 phylogenetic trees. We used the program TREEedit to render the 100 phylogenetic trees ultrametric (Rambaut and Charleston, 2002). In TREEEDIT, we used non-parametric rate smoothing and weighted rate differences across the root to generate the ultrametric trees (Sanderson, 1997). Then, using the programming language $\mathrm{R}$ and with bower type as the grouping variable, these 100 phylogenies were used to provide a range of evolutionary hypotheses to run phylogenetic ANOVAs (Garland et al., 1993; Revell, 2012). Using phytools, we conducted 1000 Brownian motion numerical simulations for each trait on the tree to obtain a null distribution of the model test statistic (F). This Monte Carlo simulated null distribution is then compared against the empirical values of Brownian motion inferred evolution for each trait to obtain a $p$-value. All data used to construct the phylogenetic trees are available in Supplementary Data Sheet 1.

\section{BEHAVIORAL ANALYSES}

In order to identify possible differences in courtship and bowerbuilding behaviors we assayed a pit-digging (Copadichromis virginalis: $\mathrm{CV}$ ) and a castle-building (Mchenga conophoros: $\mathrm{MC}$ ) species. CV and MC were chosen due to the similarity of their ecology and life histories in Lake Malawi. Both species are easily reared in a laboratory environment and display behaviors and behavioral repertoires similar to those observed in the field. To quantify male bower building activity, 10 males each of $\mathrm{CV}$ and MC were housed with 2-3 conspecific females and video recorded during peak bower building. The number of build (MC) or dig (CV) behaviors was enumerated per hour. These fish were maintained in 50-gallon rectangular tanks that had a uniform layer of $40 \mathrm{lbs}$ (about $4 \mathrm{~cm}$ in depth) of Malawi sand [CaribSea Inc]. All species are grown and maintained in the laboratory, in tanks that mimic natural conditions of $\mathrm{pH}(8.2)$, conductivity (230 uS) and temperature $\left(26^{\circ} \mathrm{C}\right)$ in a $12 \mathrm{~h}$ light $-12 \mathrm{~h}$ dark cycle, under established Georgia Institute of Technology IACUC protocols.

Ethograms for $\mathrm{MC}$ and $\mathrm{CV}$ were constructed through systematic observation of MC and CV laboratory populations. Five focal males and five focal females were observed at varying times in morning, afternoon, and evening over the course of 2 months. These fish were kept in 761 aquaria $(61 \times 55.9 \times 30.5 \mathrm{~cm}$, width $\times$ depth $\times$ height) with the same sand, $\mathrm{pH}$, conductivity, temperature, and light cycle outlined above under established Stanford University IACUC protocols. All males assayed were mature and reproductively active as indicated by nuptial coloration and territorial behavior. Each focal animal was placed in multiple social conditions over this time period in order to gather observations reflective of the natural lifestyle for both species. In both MC and CV we observed 18 mutually distinct behaviors, 17 of which were common between both species.

In order to assay behavioral transitions during courtship that may be species-specific we housed MC $(n=3)$ and CV $(n=3)$ males housed with 2-3 females of the same species. In order to observe courtship and bower-building behaviors males were allowed to develop territories and initiate the process of bowerbuilding. Once territories were established each male was filmed for 30 min during active courtship. With the ethogram as a guide we scored the time and duration of each behavior using custom functions in the MATLAB computing environment. Behavioral transition probabilities were computed by creating an $n \times n$ matrix, the dimensions of which were determined by the number of individual behaviors performed during the observation period. Each cell of the matrix corresponded to the number of transitions between each leading behavior (rows) and each following behavior (columns). Transition probabilities were computed by taking the ratio of observed transitions between leading and following 
behaviors over the total number of occurrences of each leading behavior. The resulting behavioral frequencies and probabilities were then used to construct Markov chains in order to visualize species-specific behavior patterns (Markov, 1971). Custom scripts for Graphviz visualization software were used for plotting the Markov models. In order to assay the level of stereotypy for any given behavioral transition pattern we computed transition entropy for each behavior following Miller et al. (2010). This yields a score between 0 and 1 for each behavior where a score of 0 indicates high determinism and predictability while a score of 1 indicates a complete lack determinism and predictability. We then computed transition stereotypy-the inverse of entropy-by subtracting the entropy scores by 1 . Statistical differences between MC and CV were assayed through pairwise comparisons of behavioral frequency and transition probability using the bootstrap method outlined above.

\section{ACKNOWLEDGMENTS}

We thank Lisa Becker, Samantha Hofmann, Elizabeth Fowler, and Zarek Siegel for technical help and Dr. Austin Hilliard for comments on earlier versions of the manuscript. Supported by a Stanford Bio-X Bowes Fellowship (RAY), NIGMS 101095 (RDF and JTS), NINDS 034950 (RDF), and NSF IOS 1146275 (JTS).

\section{SUPPLEMENTARY MATERIAL}

The Supplementary Material for this article can be found online at: http://www.frontiersin.org/journal/10.3389/fevo.2015. 00018/abstract

\section{REFERENCES}

Alberston, R. C., and Kocher, T. D. (2001). Assessing morphological differences in an adaptive trait: a landmark-based morphometric approach. J. Exp. Zool. 289, 385-403. doi: 10.1002/jez.1020

Albertson, R. C., Streelman, J. T., Kocher, T. D., and Yelick, P. C. (2005). Integration and evolution of the cichlid mandible: the molecular basis of alternative feeding strategies. Proc. Natl. Acad. Sci. U.S.A. 102, 16287-16292. doi: 10.1073/pnas.0506649102

Albertson, R. C., Streelman, J. T., and Kocher, T. D. (2003). Directional selection has shaped the oral jaws of Lake Malawi cichlid fishes. Proc. Natl. Acad. Sci. U.S.A. 100, 5252-5257. doi: 10.1073/pnas.0930235100

Alfaro, M. E., Bolnick, D. I., and Wainwright, P. C. (2005). Evolutionary dynamics of complex biomechanical systems: an example using the four-bar mechanism. Evolution 58, 495-503. doi: 10.1111/j.0014-3820.2004.tb01673.x

Barlow, G. W. (2008). The Cichlid Fishes: Nature's Grand Experiment in Evolution. Cambridge: Basic Books.

Bernatchez, L., Renaut, S., Whiteley, A. R., Derome, N., Jeukens, J., Landry, L., et al. (2010). On the origin of species: insights from the ecological genomics of lake whitefish. Philos. Trans. R. Soc. Lond. B Biol. Sci. 365, 1783-1800. doi: 10.1098/rstb.2009.0274

Brawand, D., Wagner, C. E., Li, Y. I., Malinsky, M., Keller, I., Fan, S., et al. (2014). The genomic substrate for adaptive radiation in African cichlid fish. Nature 513, 375-381. doi: 10.1038/nature13726

Carleton, K. L., Harosi, F. I., and Kocher, T. D. (2000). Visual pigments of African cichlid fishes: evidence for ultraviolet vision from microspectrophotometry and DNA sequences. Vision Res. 40, 879-890. doi: 10.1016/S0042-6989(99)00238-2

Cooper, W. J., and Westneat, M. W. (2009). Form and function of damselfish skulls: rapid and repeated evolution into a limited number of trophic niches. BMC Evol. Biol. 9:24. doi: 10.1186/1471-2148-9-24

Dalton, B. E., Cronin, T. W., Marshall, N. J., and Carleton, K. L. (2010). The fish eye view: are cichlids conspicuous? J. Exp. Biol. 213, 2243-2255. doi: 10.1242/jeb.037671
Danly, P. D., and Kocher, T. D. (2001). Speciation in rapidly diverging systems: lessons from Lake Malawi. Mol. Ecol. 10L, 1075-1086. doi: 10.1046/j.1365294X.2001.01283.x

Dawkins, R. (1992). The Extended Phenotype. New York, NY: Oxford University Press.

Drummond, A. J., and Rambaut, A. (2007). BEAST: Bayesian evolutionary analysis by sampling trees. BMC Evol. Biol. 2007, 7-214. doi: 10.1186/1471-2148-7-214

Duponchelle, F., Ribbink, A. J., Msukwa, A., Mafuka, J., and Mandere, D. (2000). "Depth distribution and breeding patterns of the demersal species most commonly caught by trawling in the South West Arm of Lake Malawi," in Proceedings of the Fish Ecology Report, eds F. Duponchelle and A. J. Ribbink (Lake Malawi/Nyasa/Niassa Biodiversity Conservation Project).

Franchini, P., Fruciano, C., Frickey, T., Jones, J. C., and Meyer, A. (2014). The gut microbial community of Midas cichlid fish in repeatedly evolved limnetic-benthic species pairs. PLOS ONE 9:e103923. doi: 10.1371/journal.pone. 0103923

Fryer, G., and Iles, T. D. (1972). The Cichlid Fishes of the Great Lakes of Africa: Their Biology and Evolution. New York, NY: Oliver and Boyd.

Garland, T. Jr., Dickerman, A. W., Janis, C. M., and Jones, J. A. (1993). Phylogenetic analysis of covariance by computer simulation. Syst. Biol. 42, 265-292. doi: 10.1093/sysbio/42.3.265

Goodson, J. L. (2005). The vertebrate social behavior network: evolutionary themes and variations. Horm. Behav. 48, 11-22. doi: 10.1016/j.yhbeh.2005.02.003

Gunter, H. M., Fan, S., Xiong, F., Franchini, P., Fruciano, C., and Meyer, A. (2013). Shaping development through mechanical strain: the transcriptional basis of diet-induced phenotypic plasticity in a cichlid fish. Mol. Ecol. 22, 4516-4531. doi: $10.1111 / \mathrm{mec} .12417$

Hansell, M. H. (2005). Animal Architecture. Oxford: Oxford University Press. doi: 10.1093/acprof:oso/9780198507529.001.0001

Hofmann, H. A., Beery, A. K., Blumstein, D. T., Couzin, I. D., Earley, R. L., Hayes, L. D., et al. (2014). An evolutionary framework for studying mechanisms of social behavior. Trends Ecol. Evol. 29, 581-589. doi: 10.1016/j.tree.2014.07.008

Hofmann, C. M., O'Quin, K. E., Marshall, N. J., Cronin, T. W., Seehausen, O., and Carleton, K. L. (2009). The eyes have it: regulatory and structural changes both underlie cichlid visual pigment diversity. PLOS Biol. 7:e1000266. doi: 10.1371/journal.pbio.1000266

Hofmann, C. M., O'Quin, K. E., Smith, A., and Carleton, K. L. (2010). Plasticity of opsin gene expression in cichlids from Lake Malawi. Mol. Ecol. 19, 2064-2074. doi: 10.1111/j.1365-294X.2010.04621.x

Huber, R., van Staaden, M. J., Kaufman, L. S., and Liem, K. F. (1997). Microhabitat use, trophic patterns, and the evolution of brain structure in African cichlids. Brain Behav. Evol. 50, 167-182. doi: 10.1159/000113330

Hulsey, C. D., and Garcia De Leon, F. J. (2005). Cichlid jaw mechanics: linking morphology to feeding specialization. Funct. Ecol. 19, 487-494. doi: 10.1111/j.13652435.2005.00987.x

Hulsey, C. D., García de León, F. J., and Rodiles-Hernández, R. (2006). Micro- and macroevolutionary decoupling of cichlid jaws: a test of Liem's key innovation hypothesis. Evolution 60, 2096-2109. doi: 10.1111/j.0014-3820.2006.tb01847.x

Hulsey, C. D., Mims, M. C., Parnell, N. F., and Streelman, J. T. (2010). Comparative rates of lower jaw diversification in cichlid adaptive radiations. J. Evol. Biol. 23, 1456-1467. doi: 10.1111/j.1420-9101.2010.02004.x

Hulsey, C. D., Roberts, R. J., Loh, Y. H. E., Rupp, M. F., and Streelman, J. T. (2013). Lake Malawi cichlid evolution along a benthic/limnetic axis. Ecol. Evol. 3, 2262-2272. doi: 10.1002/ece3.633

Hulsey, C. D., and Wainwright, P. C. (2002). Projecting mechanics into morphospace: disparity in the feeding system of labrid fishes. Proc. Biol. Sci. 269, 317-326. doi: 10.1098/rspb.2001.1874

Kamermans, M., and Hawryshyn, C. (2011). Teleost polarization vision: how it might work and what it might be good for. Philos. Trans. $R$ Soc. Lond. B Biol. Sci. 366, 742-756. doi: 10.1098/rstb.2010.0211

Kassam, D., Adams, D. C., and Yamaoka, K. (2004). Functional significance of variation in trophic morphology within feeding microhabitat-differentiated cichlid species in Lake Malawi. Anim. Biol. 54, 77-90. doi: 10.1163/157075604323010060

Kidd, M. R., Kidd, C. E., and Kocher, T. D. (2006). Axes of differentiation in the bower-building cichlids of Lake Malawi. Mol. Ecol. 15, 459-478. doi: 10.1111/j.1365-294X.2005.02787.x

Kocher, T. D. (2004). Adaptive evolution and explosive speciation: the cichlid fish model. Nat. Rev. Genet. 5, 288-298. doi: 10.1038/nrg1316 
Konings, A. (1990). Ad Koning's Book of Cichlids and all the Other Fishes of Lake Malawi. New Jersey, NJ: TFH Publications.

Konings, A. (2000). Malawi Cichlids in their Natural Habitat, 3rd Edn. El Paso: Cichlid Press.

Konings, A. (2007). Malawi Cichlids in their Natural Habitat, 4th Edn. El Paso: Cichlid Press.

Kusmierski, R., Borgia, G., Uy, A., and Crozier, R. H. (1997). Labile evolution of display traits in bowerbirds indicates reduced effects of phylogenetic constraint. Proc. Biol. Sci. 264, 307-313. doi: 10.1098/rspb.1997.0044

Lee, P. L., Clayton, D. H., Griffiths, R., and Page, R. D. (1996). Does behavior reflect phylogeny in swiftlets (Aves: Apodidae)? A test using cytochrome b mitochondrial DNA sequences. Proc. Natl. Acad. Sci. U.S.A. 93, 7091-7096. doi: 10.1073/pnas.93.14.7091

Lefebvre, L., and Sol, D. (2008). Brains, lifestyles and cognition: are there general trends? Brain Behav. Evol. 72, 135-144. doi: 10.1159/000151473

Lewis, P. O. (2001). A likelihood approach to estimating phylogneny from discrete morphological character data. Syst. Biol. 50, 913-925. doi: $10.1080 / 106351501753462876$

Loh, Y. H., Bezault, E., Muenzel, F. R. M., Roberts, R. B., Swofford, R., Barluenga, M., et al. (2013). Origins of shared genetic variation in African cichlids. Mol. Biol. Evol. 30, 906-917. doi: 10.1093/molbev/mss326

Loh, Y. H. E., Katz, L. S., Mims, M. C., Kocher, T. D., Soojin, V. Y., and Streelman, J. T. (2008). Comparative analysis reveals signatures of differentiation amid genomic polymorphism in Lake Malawi cichlids. Genome Biol. 9:R113. doi: 10.1186/gb-2008-9-7-r113

Lythgoe, J. H. (1968). Visual pigments and visual range underwater. Vision Res. 8, 997-1011. doi: 10.1016/0042-6989(68)90073-4

Magalhaes, I. S., and Seehausen, O. (2010). Genetics of male nuptial colour divergence between sympatric sister species of a Lake Victoria cichlid fish. Evol. Biol. 23, 914-924. doi: 10.1111/j.1420-9101.2010.01960.x

Markov, A. (1971). "Extensions of the limit theorems of probability theory to a sum of variables connected in a chain," in Appendix B of Dynamic Probabilistic Systems, Markov Models, Vol. I, ed R. Howard (New York, NY: Dover).

Martin, C. H., and Genner, M. J. (2009). A role for male bower size as an intrasexual signal in Lake Malawi cichlid fish. Behavior 146, 963-978. doi: $10.1163 / 156853908 X 396836$

McKaye, K. R., Stauffer, J. R., Turner, G. F., Konings, A., and Sato, T. (2001). Fishes, as well as birds, build bowers. J. Aquaricult. Aquat. Sci. 9, 121-133.

McKaye, D. R. (1991). "Sexual selection and the evolution of the cichlid fishes of Lake Malawi, Africa," in Cichlid Fishes: Behavior, Ecology, Evolution, ed M. Keenleyside (London: Chapman and Hall), 241-257.

Miller, J. E., Hilliard, A. T., and White, S. A. (2010). Song practice promotes acute vocal variability at a key stage of sensorimotor learning. PLoS ONE 5:e8592. doi: 10.1371/journal.pone.0008592

Moran, P., Kornfield, I., and Reinthal, P. N. (1994). Molecular systematics and radiation of the haplochromine cichlids (Teleostei, Perciformes) of Lake Malawi. Copeia 2, 274-288. doi: 10.2307/1446977

Muschick, M., Barluenga, M., Salzburger, W., and Meyer, A. (2011). Adaptive phenotypic plasticity in the Midas cichlid fish pharyngeal jaw and its relevance in adaptive radiation. BMC Evol. Biol. 11:116. doi: 10.1186/1471-2148-11-116

O'Connell, L. A., and Hofmann, H. A. (2011). Genes, hormones, and circuits: an integrative approach to study the evolution of social behavior. Front. Neuroendocrinol. 32, 320-335. doi: 10.1016/j.yfrne.2010.12.004

O'Quin, K. E., Hofmann, C. M., Hofmann, H. A., and Carleton, K. L. (2010). Parallel evolution of opsin gene expresson in African cichlid fishes. Mol. Biol. Evol. 27, 2839-2854. doi: 10.1093/molbev/msq171

Parnell, N. F., Hulsey, C. D., and Streelman, J. T. (2008). Hybridization produces novelty when the mapping of form to function is many to one. BMC Evol. Biol. 8:122. doi: $10.1186 / 1471-2148-8-122$

Parnell, N. F., and Streelman, J. T. (2013). Genetic interactions controlling sex and color establish the potential for sexual conflict in Lake Malawi cichlid fishes. Heredity 110, 239-246. doi: 10.1038/hdy.2012.73

Parry, J. W., Carleton, K. L., Spady, T., Carboo, A., Hunt, D. M., Bowmaker, J. K. (2005). Mix and match color vision: Tuning spectral sensitivity by differential opsin expression in Lake Malawi cichlids. Current Biology 15, 1734-1739. doi: 10.1016/j.cub.2005.08.010

Peichel, C. L., Nereng, K. S., Ohgi, B. L. E., Cole, P. F., Colosimo, C. A. Buerkle, C. A., et al. (2001). The genetic architecture of rapid morphological divergence between threespine stickleback species. Nature 414, 901-905. doi: $10.1038 / 414901$ a

Pollen, A. A., Dobberfuhl, A. P., Scace, J., Igulu, M. M., Renn, S. C. P., Shumway, C. A., et al. (2007). Environmental complexity and social organization sculpt the brain in Lake Tanganyikan cichlid fish. Brain Behav. Evol. 70, 21-39. doi: $10.1159 / 000101067$

Posada, D. (2008). jModelTest: phylogenetic model averaging. Mol. Biol. Evol. 25 1253-1256. doi: 10.1093/molbev/msn083

Rambaut, A., and Charleston, M. (2002). TreeEdit: Phylogenetic Tree Editor v.1.0 Alpha 10. Available online at: http://evolve.zoo.ox.ac.uk/software/TreeEdit/ main.html.

Revell, L. J. (2012). phytools: An R package for phylogenetic comparative biology (and other things). Method Ecol. Evol. 3, 217-223. doi: 10.1111/j.2041210X.2011.00169.x

Roberts, R. B., Ser, J. R., and Kocher, T. D. (2009). Sexual conflict resolved by invasion of a novel sex determiner in Lake Malawi cichlid fishes. Science 326, 998-1001. doi: 10.1126/science.1174705

Robinson, G. E., Fernald, R. D., and Clayton, D. F. (2008). Genes and social behavior. Science 322, 896-900. doi: 10.1126/science.1159277

Ronquist, F., Teslenko, M., van der Mark, P., Ayres, D. L., Darling, A., Höhna, S. et al. (2012). MrBayes 3.2: efficient Bayesian phylogenetic inference and model choice across a large model space. Syst. Biol. 61, 539-542. doi: 10.1093/sysbio/sys029

Rundle, H. D., Nagel, L., Boughman, J. W., and Schluter, D. (2000). Natural selection and parallel speciation in sympatric sticklebacks. Science $287 \mathrm{~L}, 306-308$ doi: $10.1126 /$ science 287.5451 .306

Sabbah, S., Gray, S. M., Boss, E. S., Fraser, J. M., Zatha, R., and Hawryshyn, C. W. (2011). The underwater photic environment of Cape Maclear, Lake Malawi: comparison between rock- and sand-bottom habitats and implications for cichlid fish vision. J. Exp. Biol. 214, 487-500. doi: 10.1242/jeb. 051284

Sabbah, S., Laria, R. L., Gray, S. M., and Hawryshyn, C. W. (2010). Functional diversity in the color vision of cichlid fishes. BMC Biol. 8:133. doi: 10.1186/17417007-8-133

Sanderson, M. J. (1997). A nonparametric approach to estimating divergence times in the absence of rate constancy. Mol. Biol. Evol. 14, 1218-1231. doi: 10.1093/oxfordjournals.molbev.a025731

Schluter, D., and Price, T. (1993). Honesty, perception and population divergence in sexually selected traits. Proc. Biol. Sci. 253, 117-122. doi: 10.1098/rspb.1993.0089

Seehausen, O., van Alphen, J. J. M., and Witte, F. (1997). Cichlid fish diversity threatened by eutrophication that curbs sexual selection. Science 227, 1808-1811. doi: 10.1126/science.277.5333.1808

Smith, A. R., Ma, K., Soares, D., and Carleton, K. L. (2012). Relative LWS cone opsin expression determines optomotor thresholds in Malawi cichlid fish. Genes Brain Behav. 11, 185-192. doi: 10.1111/j.1601-183X.2011.00739.x

Stauffer, J. R., LoVullo, T. J., and McKaye, K. R. (1993). Three new sanddwelling cichlids from Lake Malawi, Africa, with a discussion of the status of the genus Copadichromis (Teleostei: Cichlidae). Copeia 4, 1017-1027. doi: $10.2307 / 1447079$

Streelman, J. T., and Danley, P. D. (2003). The stages of vertebrate evolutionary radiation. Trends Ecol. Evol. 18, 126-131. doi: 10.1016/S0169-5347(02) 00036-8

Stuart, A. E., and Hunter, F. F. (1998). Phylogenetic placement of Ectemnia, an autapomorphic black fly (Diptera: Simuliidae). Can. J. Zool. 76, 1942-1948. doi: $10.1139 / \mathrm{z} 98-140$

Svanbäck, R., and Eklöv, P. (2002). Effects of habitat and food resources on morphology and ontogenetic trajectories in perch. Oecologia 131, 61-70. doi: 10.1007/s00442-001-0861-9

Tinbergen, N. (1963). On aims and methods of ethology. Z. Tierpsychol. 20, 410-433. doi: 10.1111/j.1439-0310.1963.tb01161.x

Turner, G. F., and Burrows, M. T. (1995). A model of sympatric speciation. Proc. Biol. Sci. 260, 287-292. doi: 10.1098/rspb.1995.0093

Uy, J. B. G. (2000). Sexual selection drives rapid divergence in bowerbird display traits. Evolution 54, 273-278. doi: 10.1111/j.0014-3820.2000.tb00027.x

Wagner, C. E., Harmon, L. J., and Seehausen, O. (2012). Ecological opportunity and sexual selection together predict adaptive radiation. Nature 487, 366-369. doi: $10.1038 /$ nature 11144 
Conflict of Interest Statement: The authors declare that the research was conducted in the absence of any commercial or financial relationships that could be construed as a potential conflict of interest.

Received: 06 November 2014; accepted: 11 February 2015; published online: 18 March 2015.

Citation: York RA, Patil C, Hulsey CD, Anoruo O, Streelman JT and Fernald RD (2015) Evolution of bower building in Lake Malawi cichlid fish: phylogeny, morphology, and behavior. Front. Ecol. Evol. 3:18. doi: 10.3389/fevo.2015.00018
This article was submitted to Behavioral and Evolutionary Ecology, a section of the journal Frontiers in Ecology and Evolution.

Copyright (C) 2015 York, Patil, Hulsey, Anoruo, Streelman and Fernald. This is an open-access article distributed under the terms of the Creative Commons Attribution License (CC BY). The use, distribution or reproduction in other forums is permitted, provided the original author(s) or licensor are credited and that the original publication in this journal is cited, in accordance with accepted academic practice. No use, distribution or reproduction is permitted which does not comply with these terms. 